\title{
Wie beeinflussen interkulturelle Werte das Top Management?
}

\section{Forscher diskutieren aktuelle Trends während des vierten EIASM-TMT-Workshops in Kopenhagen}

Werden Top Manager durch ihren kulturellen Hintergrund in ihren Werten und Präferenzen beeinflusst? Diese Frage stand im Fokus des zweitägigen Workshops zur TopManagement-Team-Forschung des European Institute for Advanced Studies in Management (EIASM). In seiner Keynote-Rede reflektierte Christophe Boone von der Universität Antwerpen, Belgien, die Gründe für den langanhaltenden Erfolg dieses Forschungsfeldes und hob in diesem Zusammenhang innovative Ansätze aktueller Studien hervor. So schlossen beispielsweise die Autoren eines Artikels aus der Größe des Bildes des CEOs in einem Geschäftsbericht auf Narzissmus in seiner Persönlichkeit. Boone regte für die Fortführung der Forschung ferner an, beispielsweise auch die Wortwahl in Aktionärsbriefen genauer zu untersuchen. Man könne daran ablesen, wie viel Wert der Vorstand auf Innovationen lege.

In einer zweiten Keynote-Rede machte auch Ruth V. Aguilera von der University of Illinois at Urbana-Champaign, USA, Vorschläge für neue Richtungen in der Forschung wie beispielsweise Diversitätsfragen oder noch gezieltere internationale Vergleiche. Weiterhin stellte Aguilera eine aktuelle
Studie zu unmoralischem Verhalten in Aufsichtsräten im internationalen Vergleich vor, welches von Earnings Management bis hin zu bewusstem Täuschen gehen kann.

Neben den Keynote-Reden spiegelten auch die vorgestellten Papers die breite Vielfalt innerhalb der Top-ManagementForschung wider. Während mehrere Papers die Aufsichtsratsstruktur untersuchten, legten andere Forscher den Fokus auf spezielle Bereiche wie beispielsweise Familienunternehmen oder akademische Start-ups.

Der seit 2009 jährlich vom EIASM organisierte Workshop fand am 17. und 18. Oktober 2013 in Kopenhagen, Dänemark, statt. Ihn zeichnet seine kleine, auf das Forschungsgebiet fokussierte Teilnehmergruppe aus, in der besonders intensive und konstruktive Debatten möglich sind. Neben den spannenden Vorträgen und Diskussionen boten eine Bootsfahrt durch die Kanäle der Stadt und ein Abendessen im traditionsreichen Tivoli-Freizeitpark reichlich Gelegenheit, sich auch auf persönlicher Ebene zum Thema auszutauschen und neue Kontakte zu knüpfen.

Melanie Schneider, Vallendar

\section{Ein Plädoyer für mehr unternehmerischen Wagemut statt zögerlicher Managementpläne! ᄀ}

springer-gabler.de

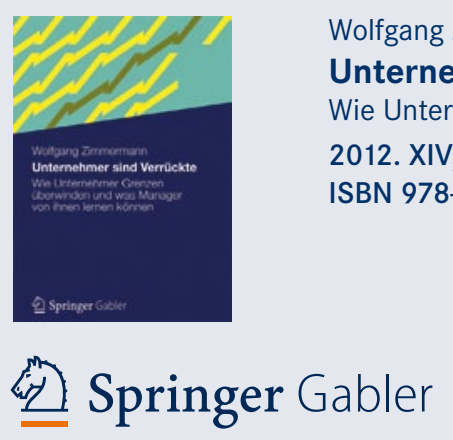

